\title{
Explaining the legitimizing function of expert knowledge: how France got away with pain in farm animals
}

\author{
Vincent Caby ${ }^{1}$
}

Accepted: 2 December 2020 / Published online: 6 January 2021

(c) The Author(s) 2020

\begin{abstract}
Scholars have long investigated connections between types of knowledge use and types of policy subsystem. Yet, most of them focus on the learning function of expert information. The legitimizing function of knowledge-when expertise serves as a substitute for decision (Boswell in J Eur Public Policy 15(4):471-488, 2008) has attracted less attention. An empirically validated explanation of this function is still missing. This article tests existing hypotheses regarding which features of the subsystem are conducive to the legitimizing function. The demonstration rests upon a case study: France's Ministry of Agriculture's commissioning of INRA to carry out a systematic literature review on pain in farm animals. Two types of factors are involved in the legitimizing function of knowledge: environmental mechanisms (an adversarial policy subsystem, concentration of policy authority) and relational mechanisms (coalitions displaying epistemic uncertainty and exerting pressures on the source of policy authority, a policy broker mitigating the conflict between the two coalitions).
\end{abstract}

Keywords Knowledge utilization · Legitimizing function · Blame avoidance · Systematic literature reviews $\cdot$ Animal pain $\cdot$ Ritual slaughter

\section{Introduction}

Pioneer investigations of the knowledge utilization literature found that expert knowledge ${ }^{1}$ had different "meanings" for policymakers (Weiss 1979), who may use expertise "instrumentally" (Knorr 1976, 1977) in the making of public policies. In this case, knowledge may serve to learn about a public problem (the

\footnotetext{
1 Following Weible's definition of expert-based information: "Content generated by professional, scientific and technical methods of inquiry" (2008, p. 615).

Vincent Caby

vincent.caby@uclouvain.be

1 Institut de sciences politiques Louvain-Europe (ISPOLE), Louvain-La-Neuve, Belgium
} 
"knowledge-driven model") or to decide between different policy solutions (the "problem-solving model") (Weiss 1979).

Policymakers may also use expert information "symbolically" (Knorr 1976) in the game of blame avoidance (Weaver 1986). In this case, policymakers may employ expertise to "substantiate" their preferred policy solution (Boswell 2008) (for an early illustration, see Nelkin's description of how the Massachusetts Port Authority commissioned, shaped and used a series of expert reports to support the expansion of the Boston Logan Airport (1975)). Scholars refer to this first, symbolic type of knowledge use through a variety of overlapping concepts, including "political model" (Weiss 1979), "political use" (Jasanoff 1990; Weible 2008; Daviter 2015), and "strategic substantiating" (Schrefler 2010; Rimkuté 2015).

Expert information may also serve as a substitute for decision (Boswell's "legitimizing function" (2008)). One of the first definitions of this second, symbolic type of knowledge use was given by Knorr: "by initiating, distributing and publishing a research report, a government official (...) tries to signalize to those concerned that something is done about the problem-while proper decisions and measures that should be taken are being postponed or neglected" (1976, p. 13). In this situation, the primary objective of policymakers who commission the production of new knowledge is to send signals to other policy actors, as part of blame-avoiding strategies (Weaver 1986) (typically agenda limitation strategies). There may be cues of responsiveness, academic prestige (Weiss 1979), competence, and rationality (Radaelli 1995; Schrefler 2010; Rimkuté 2015). Policymakers expect these signals to help them maintain and increase their legitimacy (Weiss 1979; Radaelli 2009; Boswell 2008; Schrefler 2010), and ultimately to preserve and extend their jurisdiction (Boswell 2008). Scholars likewise rely on a variety of concepts to refer to this type of knowledge, such as "tactical model" (Weiss 1979) and "symbolic use" (Hertin et al. 2009; Radaelli 2009; Schrefler 2010; Rimkuté 2015).

In the tradition of compared politics - and based on late studies from the knowledge utilization literature (Oh and Rich 1996) — some scholars have suggested that a certain context is conducive to a particular type of knowledge use (Sabatier and Jenkins-Smith and Sabatier 1993; Radaelli and Dente 1996). This new research agenda aroused an interest in the public policy community. In particular, Advocacy Coalitions Framework (ACF) scholars started empirically investigating connections between types of knowledge use and types of policy subsystem. The ACF consists in studying advocacy coalitions: "actors who share policy core beliefs and coordinate their behavior in nontrivial ways over extended periods of time toward some sort of shared outcome in a policy subsystem" (Weible et al. 2020, p. 7). Such coalitions may vary according to five attributes: the nature of policy actors, their belief systems, the extent to which they coordinate their political activities, their resources, and their stability (policy actors being "individuals or groups (...) from inside or outside of government who are (or seek to be) influential in the policymaking process (...), and who regularly engage in attempting to exert that influence") (Ibid.). Minimal conditions for an advocacy coalition to exist are shared policy core beliefs_- whether and how a government should or should not act in relation to a problem or concern" (Ibid., p. 10)-between at least two different policy actors. The number and the nature of coalitions determines the type of policy subsystem, which 
may in turn affect the type of knowledge use (Weible 2008). In this endeavor, most ACF scholars focused on which characteristics of the policy subsystem were conducive to the learning function of expert information (see: Norton 2005; Scholz and Stiftel 2005; Gunderson and Light 2006; cited in Weible and Sabatier 2009).

While less attention used to be paid to the symbolic uses of knowledge (Daviter 2015 , p. 492), in recent years, this has changed to a certain extent. Some scholars have started empirically investigating which features of the policy subsystem are conducive to the substantive function of expert information (Boswell 2008; Rimkuté 2015). On the other hand, hypotheses regarding the factors conducive to the legitimizing function remain untested (Boswell 2008; Radaelli 2009; Schrefler 2010; Rimkuté 2015). An empirically validated explanation of the legitimizing function of expert knowledge is still missing.

This article takes a first step toward filling this research gap by testing existing hypotheses regarding which characteristics of the policy subsystem are conducive to the legitimizing function of knowledge. Factors are aggregated within a Tilly-like process-based account, rather than a two-by-two matrix.

As the demonstration is based on the study of the use of a systematic literature review, this article also sheds light on how policymakers may use reviews, metaanalyses and other types of systematic expertise-a so far under-researched dimension (Bédard and Ouimet 2017, p. 145)

The existing literature is reviewed in the first section. Competing hypotheses are identified, derived from two-by-two matrices. Potential factors are located at three different levels: the subsystem level, the organization level, and the problem level. Crucially, these hypotheses remain untested.

The second section presents the fieldwork: a case study of when and why the French Ministry of Agriculture commissioned France's National Institute of Agricultural Research (INRA) to carry out a systematic literature review on pain in farm animals. The case study draws on in-depth interviews with policymakers and stakeholders and on a thorough review of the Ministry's public and non-public records. Based on strong evidence that the commissioning of the review served a legitimizing function, the features of the policy subsystem that proved essential to this type of knowledge utilization are identified.

In the third section, using concepts from the advocacy coalition framework, the story of how the Ministry of Agriculture came to commission the systematic literature review is recounted. Deep core, policy core beliefs, and policy images of policy actors of the French livestock sector are highlighted, as well as the extent of coordination of political activities in the sector. Lastly, findings are summarized and implications for future research are discussed.

\section{Theoretical framework: a series of competing and untested hypotheses on the legitimizing function of expert knowledge}

Jenkins-Smith and Sabatier first hypothesized that the extent to which policymakers learn from expertise depends on certain features of the policy subsystem (1993). Shortly thereafter, ACF scholars associated each type of knowledge use with a 
specific set of idiosyncrasies located at the subsystem level (Radaelli and Dente 1996; Weible 2008). A small number of them focused on both the substantiating and legitimizing functions of expert knowledge (Boswell 2008; Radaelli 2009; Schrefler 2010; Daviter 2015; Rimkuté 2015). Their research work provides a series of hypotheses to test.

Building two-by-two matrices (if the subsystem presents both characteristics $X 1$ and $X 2$, expert information will likely serve the function $Y$ ), most scholars suggested that for the legitimizing function to occur, a combination of two sub-systemic factors is required (Boswell 2008; Schrefler 2010; Rimkuté 2015). More rarely, they hypothesized that a single feature of the subsystem could foster this type of knowledge use (Radaelli 2009). A compared analysis of their research indicates that they disagree on which factors are essential. Scholars highlight different characteristics, located at distinct levels: the policy subsystem, organizations involved in the production of new knowledge, the problem at stake. This is due to the different research traditions in which they operate, besides the knowledge utilization literature and the ACF: isomorphism (e.g., Boswell 2008); regulation and regulatory agencies (e.g., Schrefler 2010); policy learning (e.g., Radaelli 2009). We identify the six following hypotheses.

H1 An adversarial policy subsystem - a subsystem in which the coordination of political activities within a coalition includes efforts to outmaneuver the rival coalition (and hence, in which there is no cross-coalition coordination) (Weible et al. 2020, p. 12)-fosters the legitimizing function of expert information ${ }^{2}$ (Boswell 2008, pp. 474-475; Radaelli 2009, pp. 1148-1149; Schrefler 2010, pp. 319-321; Rimkute 2015, pp. 118-119). The opposite of an adversarial subsystem is a collaborative subsystem - a subsystem in which cross-coalition coordination is common (Weible et al. 2020).

H2 Apolitical organization-an organization which derives its legitimacy from publicly endorsing certain norms and values, and from being viewed by the public as addressing public problems (Brunson 2002) - is more likely to use the commissioning of new knowledge as a substitute for decision than action organization (Boswell 2008, pp. 473-475). Unlike political organizations, action organizations derive their legitimacy from their outputs (Brunson 2002).

H3 Low internal scientific capacity in the organization commissioned to produce new knowledge favors the legitimizing function of expertise (Schrefler 2010, p. 315; Rimkuté 2015, pp. 118-119).

\footnotetext{
${ }^{2}$ Alternative expressions such as: an unstable organizational field, a high level of conflict between actors, a high level of pressure on organizations involved in the production of new knowledge, can be found in the literature.
} 
H4 A low level of analytical tractability of the problem at stake ${ }^{3}$ fosters the legitimizing function of expert knowledge (Boswell 2008, p. 475; Schrefler 2010, pp. 319-321).

H5 The degree of media attention to the problem at stake ${ }^{4}$ has limited influence on the type of knowledge use (Schrefler 2010, pp. 317-318).

H6 The concentration of policy authority (i.e., the power to regulate the policy subsystem) in the hands of a single policy actor is conducive to the legitimizing function of expert knowledge ${ }^{5}$ (Daviter 2015, pp. 499-501).

These six hypotheses have not been tested yet. Some studies have taken the form of literature reviews (Schrefler 2010; Daviter 2015). As such, they are speculative-which their authors readily admit: "Although empirical testing falls beyond the scope of this article, a short illustration of cases in which the above hypotheses unfold can contribute to clarifying the explanatory typology" (Schrefler 2010, p. 322). A few scholars carried out empirical investigations, but focused on types of knowledge use others than the legitimizing function of expertise: Radaelli concentrated on learning (2009) and Rimkuté on the substantiating function (2015).

Finally, Boswell tested a first series of hypotheses regarding which features of the subsystem are conducive to the legitimizing function of knowledge, using a case study approach (2008). She investigated when and how the Directorate-General for Justice, Liberty, and Security (DG JLS) used the expertise of the European Migration Network (EMN). Due to certain features of the subsystem [the political nature of the DG, its preference for a technocratic form of justification, its unstable organizational field, and the contested policy area in which it operates (immigration)], she assumed that the DG would primarily use the expertise of the EMN to substantiate its preferred policy solutions. Yet, empirical evidence led to "nuanced" findings (Ibid., p. 485). Boswell concluded that the EMN served a legitimizing function in its early days, before serving a substantiating function at a later stage-despite the absence of any major change in the subsystem (besides the evolution of the DG policymakers' intentions toward the EMN). Ultimately, the case study fell short of distinguishing essential factors of the legitimizing function of knowledge from those of the substantiating function.

Here, the research gap is arguably twofold. To be sure, an empirically validated explanation of the legitimizing function of expertise is still missing. Yet, there is also a need to better link together factors of the legitimizing function. As Rimkute put it: "We lack a detailed theoretical understanding of the mechanisms that induce different behavioral patterns in expertise use (...). A problem occurs when one

\footnotetext{
3 Scholars also use the expression: a high level of epistemic uncertainty.

4 Or saliency. Schrefler argues that the degree of media attention to the problem at stake is an endogenous factor deriving from coalitions' strategies (2010, pp. 317-318).

5 Daviter originally hypothesized that a fragmented distribution of policy authority at the subsystem level is conducive to the substantiating function of expert information (2015, pp. 499-501).
} 
attempts to grasp which of these explanatory factors (...) and how they can be combined into a theoretically coherent causal explanation" (2015, p. 115).

What if there are more essential factors than a two-by-two matrix can include? How do factors interlink? To answer these questions requires examining the epistemological rationale behind matrices. Matrices make it possible to unveil laws: "the search for necessary and sufficient conditions of stipulated outcomes" through "studies of covariation among presumed causes and presumed effects" (Tilly 2001, p. 23). Yet, matrices do not "explain salient features of episodes, or significant differences among them, by identifying within those episodes robust mechanisms [influences or alterations] of relatively general scope" (Ibid., pp. 24-25). The latter is the essence of process-based accounts. Here, I argue that the turn from two-by-two matrices to process-based accounts constitutes a promising avenue in the study of the legitimizing function of expertise. Not only do process-based accounts better display the logical order in which factors occur, but they also allow for the aggregation of mechanisms of different kinds (environmental, cognitive, and relational), located at various levels (micro and macro) (Ibid.).

Therefore, the objective of this article is to test existing hypotheses regarding which characteristics of the policy subsystem are conducive to the legitimizing function of knowledge and aggregate factors within a process-based account.

\section{Methodology: a single case study approach}

The six hypotheses will be tested against a single case: the French Ministry of Agriculture's commissioning of France's National Institute of Agricultural Research to carry out a systematic literature review on pain in farm animals (INRA 2009).

A single case study approach proves useful to explain when and why a particular type of knowledge use occurs. First, a case study approach is well-suited to specifying links between causal factors and outcomes (Blatter and Haverland 2012; Rohlfing 2012; cited in Rimkuté 2015, p. 120). It allows us to identify (and reject) non-essential factors. Focusing on a single case also allows for a more refined explanation of how certain features of the subsystem may foster a particular type of knowledge use (Ibid.; Schrefler 2010, p. 325). Boswell (2008) and Rimkuté (2015) used a single case study approach to investigate the substantiating function of expertise. Boswell obtained "nuanced" results (see supra). This is most likely due to the novelty of her research subject and the scope of her study, which looked at how the DG JLS used expert knowledge from the newly created EMN between 2002 and 2008. Over 6 years, the DG's policymakers had plenty of time to gauge and rethink the value of this new informational output, as well as the purpose it could serve. This investigation stresses the importance of focusing on types of expert information policymakers are familiar with, over short periods. By doing this in her study on the production of a report on pesticides by the European Food Safety Authority (EFSA)—Rimkuté was able to distinguish between essential factors and non-essential factors of the substantiating function of knowledge.

The selection of the 2008 Ministry of Agriculture's commissioning of an INRA systematic literature review on pain in farm animals as a case study is based on 
several criteria. First, INRA reviews fall into the category of expert-based information (see definition above). They consist in the critical analysis of thousands of scientific publications on a certain public problem by a group of academic experts from different disciplines. Their primary goal is to provide answers to the questions of the commissioning policymakers (INRA 2009, pp. 3-4).

The case selection also takes into account lessons learned from Boswell's investigation. Policymakers within the Ministry of Agriculture are familiar with INRA systematic literature reviews. They have commissioned several of them since 2002 (Sabbagh et al. 2014). Besides, we focus on a short period: from the commissioning of one particular review to its publication.

The case selection proceeded as follows. First, exploratory semi-structured interviews were conducted with the Ministry's policymakers who commissioned INRA reviews - at both administration and cabinet level [since they may have different information needs (Coleman 1972)]. Interviews focused on expected use at the time of commissioning as well as effective use at the time of publication. Policymakers' testimonies provided strong evidence that the commissioning of one particular review served a legitimizing function: the 2009 report on pain in farm animals. This preliminary step made it possible to avoid Collins' experimenter's regress (1981). The empirical validation of hypotheses requires the experimenter to possess a solid and consensual indicator. Yet, to determine whether his indicator is solid or not, the experimenter must make sure that it only indicates valid results. This of course requires knowing the results beforehand, placing the experimenter in a Catch-22 situation. Here, the author knew that INRA's review on animal pain served a legitimizing function from the testimony of commissioning policymakers ${ }^{6}(n=3)$, before investigating which features of the policy subsystem are conducive to the latter type of knowledge utilization. This makes INRA's systematic literature review on pain in farm animals a typical case, regarding its outcome.

Here, it is worth noting that moderately old cases like this one (while the review was commissioned in 2008 and published in 2009, investigations of the context of its production for this research began in 2016) provide more data than others. The study of recent cases is hindered by the reluctance of policymakers in office to discuss current issues. At the other end of the spectrum, it is often difficult to examine older cases because the interviewees may not remember details and indulge in expost reinterpretations.

\footnotetext{
6 "We were facing headwinds (...). There were animal welfare associations, which were very proactive, sometimes with a never-say-die attitude. There were professional breeders, which were more reserved but concerned"; "Regarding the Ministry's position, [the commissioning] was an easy way-and a rather cheap one-to show that we were taking care of the matter (...). It's a way of saying: "it's an issue we're getting to grips with". And it's normal, when you're getting to grips with an issue, to start by taking stock of the situation (...). Not to mention it is not a very committing decision" (Interview, Ministry of Agriculture, 2017).

"When we don't know what to do, sometimes we do a study (...). And it's a good thing [to commission a study] because this way, we're going to be able to work on other issues for the next 2 years" (Interview, Ministry of Agriculture, 2016).
} 
To test the six hypotheses here, the policy subsystem of the French livestock sector was reviewed using different data sources and collection techniques. First, semi-structured interviews with policymakers, stakeholders (representatives from animal welfare organizations, breeders' organizations, and INRA management), and researchers specializing in pain in farm animals $(n=11)$ were conducted. All interviewees were asked about their position at the time of the INRA review, their relationship with other policy actors, their role in its process and management (e.g., the sequence of events leading to the commissioning), their opinion regarding the terms of reference (the perimeter, the expert panel) and conclusions (their robustness and novelty, their reception and impact on the livestock sector). The interviewer dug deeper into some questions and issues depending on the position and role of interviewees (e.g., the distribution of policy authority in the subsystem was the subject of an extensive discussion with representatives from the Ministry of Agriculture). Second, experts in charge of drafting the report under the supervision of INRA were surveyed using an online survey ( $R R=40 \%$. Out of the 20 experts, 8 responded). In addition to previous questions, the questionnaire focused on obstacles encountered during the production process of the INRA review (e.g., disputes between experts, and between experts and INRA management). Third, stakeholders' public and nonpublic records (including the Ministry's) were reviewed: press releases, action plans, minutes of meetings, private correspondence, etc. These data collection techniques have all been recognized by ACF scholars as "valid ways to measure coalitions" (Weible et al. 2020, p. 6).

As for data analysis techniques, a deductive four-step coding strategy was used, following ACF methodological guidelines (identify the subsystem, its policy actors, their belief systems and the extent to which they coordinate their political activities) (Weible et al. 2020, p.6). Such a strategy falls into the category of content analysis. ${ }^{7}$ Codes were derived from the ACF. In interviews transcripts, survey answers and archives, policy actors and their deep core beliefs were identified ("fundamental normative orientations" such as religious beliefs), as well as their policy core ("normative and empirical beliefs concerning policy subsystems" such as positions on problem severity and cause or on policy solutions) (Weible and Ingold 2018), and their policy images ["projected social constructions or public translations of a coalition's beliefs that frame events and serve as sound bites, campaign slogans, and causal stories" (Weible 2008, p. 623)]. A single coder used the CAQDAS ATLAS.ti when applying belief system codes to interview transcripts. We measured the degree of coordination of their political activities: strong ("activities agreed upon and acknowledged by coalition actors") or weak ("activities that are in sync toward achieving a common goal but are not jointly agreed upon") (Weible and Ingold 2018). During this process, interviewees' answers to questions such as "What was the state of knowledge on pain in farm animals?" and "What do you think of the actions of policy actor X?" were particularly revealing. On this basis, and following Weible et al. (2020), all groups of policy actors who shared policy core

\footnotetext{
7 "The systematic, objective, quantitative analysis of message characteristics" using codes "developed a priori in a primarily deductive process" (Neuendorf 2019: pp. 212-215).
} 
beliefs and coordinated their political activities to some extent were categorized as advocacy coalitions. All policy actors who mitigated conflict between rival coalitions (Ibid., p. 8) were categorized as policy brokers. The number and the nature of coalitions allowed us to identify the nature of the policy subsystem (adversarial vs. collaborative).

\section{Empirical analysis: the INRA systematic literature review on animal pain}

In this section, the context in which the Ministry of Agriculture commissioned INRA to carry out a systematic literature review on animal pain is examined for the purpose of testing the aforementioned six hypotheses on the legitimizing function of expert knowledge. Factors are located at three different levels. At the subsystem level, the presence of advocacy coalitions (policy actors' shared belief systems and coordinated political activities) and the distribution of policy authority are reviewed. Features of the public problem are examined, namely media coverage and complexity (the existence of an epistemic community, the stock of existing knowledge, uncertainty regarding the consequences of policy solutions). At the organizational level, the nature of both the Ministry commissioning new knowledge (political vs. action) and of the research institute in charge of its production (low vs. high scientific capacity) are considered. The section follows the sequence of events leading to the commissioning.

\section{Animal welfare organizations take action}

In the French livestock sector of the late 2000s, a first advocacy coalition brought together animal welfare organizations such as the Oeuvre d'assistance aux bêtes d'abattoir (OABA) or the Brigitte Bardot Foundation (BBF). The deep core belief in NGOs was the protection of animal welfare, entailing policy core beliefs such as the limitation of farming and slaughter practices that are painful for farm animals. Organizations were particularly opposed to ritual slaughter-with no prior stunning-which they sought to regulate more strictly, if not to prohibit. At this time, French law granted ritual slaughter a derogatory authorization, subject to conditions. ${ }^{8}$ Organizations displayed a policy image which put emphasis on the suffering of farm animals:

Have you ever witnessed how ritual slaughter is done (...)? A cow arrives in the box, someone grabs her throat and cuts it halfway through - she's still fully conscious (...). She suffers agony for on average three minutes, sometimes five

\footnotetext{
8 "Stunning of animals is compulsory before slaughter or killing, with the exception of the following cases: 1. Ritual slaughter (...)"; "Before ritual slaughter, the mechanical immobilization of bovine, ovine and caprine animals is compulsory. The immobilization must be maintained during the bleeding"; " In: Decree $\mathrm{N}^{\circ} 2003-768$ of 1 Aug. 2003.
} 
or six, exceptionally fourteen (...) the animal is half decapitated, it convulses, it moos, there is blood (...). This is suffering (Interview with an animal welfare organization representative, 2017).

Animal welfare organizations were disappointed by the low priority given to animals at the 2007 Grenelle de l'Environnement ${ }^{9}$ - a government-organized set of roundtables on environmental and agricultural policies. From 2007, they developed communication campaigns targeting both public opinion ${ }^{10}$ and the President of the Republic Nicolas Sarkozy. This dual strategy took the form of joint open letters (displaying a strong coordination) and closed meetings. ${ }^{11}$ It benefited from the close relationship ${ }^{12}$ between animal welfare organizations and Nicolas Sarkozy-a connection established when he was Minister of the Interior and presidential candidate, between 2005 and 2007. This strategy proved successful. In early 2008, the President of the Republic asked the Minister of Agriculture Michel Barnier to organize Les Rencontres Animal et société-a set of roundtables on the topic of animals ${ }^{13}$.

In the French livestock sector, policy authority is concentrated in the Bureau de la protection animale. The Bureau is located within the Direction générale de l'alimentation, which is placed under the authority of the Minister of Agriculture, ${ }^{14}$ who in turn reports to the President of the Republic. As for its jurisdiction, the Bureau prepares, implements, and evaluates all regulations related to farm animals (e.g., the Bureau was behind the memorandums on ritual slaughter).

The stated objective of the Rencontres Animal et société was to "meet the challenge [of animal welfare] by reconciling the preservation of our cultural and religious heritage with animal welfare". ${ }^{15}$ To this end, the Ministry of Agriculture set up roundtables bringing together animal rights activists, breeders, researchers, and elected officials. Discussions were supposed to feed into the development of a new consensual action plan. One roundtable was in charge of finding solutions to the problem of animal pain in ritual slaughter. ${ }^{16}$

\footnotetext{
9 "[The Grenelle] brought together a lot of people (...) to discuss environmental issues (...). [Animal welfare organizations] considered themselves as the poor cousin of the roundtables" (Interview, Ministry of agriculture, 2017).

10 "We came up with leaflets, we bought advertising space in newspapers" (Interview, Animal welfare organization, 2017).

${ }^{11}$ One representative of an animal welfare organization mentioned: "Letters, meetings and meetings again" (2017).

${ }^{12}$ E.g.: Letter from the Minister of the Interior to the President of the BBF, 22 Dec. 2006, Ministry of the Interior.

${ }^{13}$ For a representative of a breeders' organization: "There was this increasing pressure coming from NGOs (...). Until Sarkozy (...) unilaterally decided that the Rencontres Animal et société would take place" (2017).

14 "As for farm animals, the Ministry of Agriculture [is responsible]" (Interview, Ministry of Agriculture, 2016).

${ }^{15}$ Letter from the President of the Republic to the Minister of Agriculture, 2 Feb. 2008, Presidency of the Republic.

${ }^{16}$ Press kit. Les Rencontres Animal et société, 2008, Ministry of Agriculture.
}

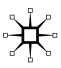




\section{Breeders' and religious organizations fight back}

The roundtables took place in spring 2008. On this occasion, animal welfare organizations reiterated their opposition to ritual slaughter. Other policy actors from the livestock sector were able to define and express their position. For breeders' and religious organizations, the Rencontres provided an opportunity to join forces and form a second advocacy coalition. Muslim and Jewish organizations stated their opposition to any new regulation of ritual slaughter (their policy core belief). The deep core belief of religious leaders required ensuring compliance with Scriptures: "For Chief Rabbi [A] (...) prior stunning is contrary to Judaism". ${ }^{17}$ Clergymen displayed a policy image that emphasized the low level of pain felt by animals undergoing ritual slaughter, as well as their opponents' prejudice against religion:

For Chief Rabbi [A] (...) the point of contention is prior stunning (...). [its ban] is absolutely excluded. If it were to be imposed in France, Jews would no longer consume meat (...), we would find ourselves in a situation comparable to that of Switzerland, whose reasons for prohibiting ritual slaughter (...) were intended to limit the entry of Jews onto the territory (...). When ritual slaughter is performed by the book, it does not cause greater suffering of the animal"; "The Rector of the Mosque [B] confirms [these] observations. He explains that ritual slaughter is not as inhuman and cruel as one might think (Roundtable, May 7th, 2008, Ministry of Agriculture).

Breeders' organizations aligned themselves with religious organizations. The former declared themselves in favor of maintaining existing legislation and practice (their policy core belief). However, the breeders' deep core belief was the survival and profitability of their livestock businesses, which required them to prevent the adoption of new standards that would increase their production costs. A central part of the policy image they displayed was the question of the economic survival of French livestock businesses: "Mr. [C] remarks (...): the adoption of penetrating captive bolts would require changing equipment in all slaughterhouses, with dire economic consequences". ${ }^{18}$ Another indication of the rather weak coordination at the basis of this second coalition is that the religious leaders and breeders exchanged arguments. ${ }^{19}$

Here, it is worth noting that the Rencontres received little coverage in the national media. In 2008, the newspapers Le Monde and La Croix, respectively, dedicated three and two articles to the Rencontres. Le Figaro and Libération did not cover the event. In comparison, leaks of hidden camera footage of slaughterhouses were the subject of a dozen of articles in these newspapers in 2016.

\footnotetext{
17 Ibid.

18 Minutes, Roundtable, 7 May 2008, Ministry of Agriculture.

19 For a representative of a breeders' organization: "[The position of animal welfare organizations] is a little borderline: it is somewhere between the actual issue of ritual slaughter and religious prejudice" (2017).
} 


\section{The Ministry of agriculture sits on the fence and commissions a systematic literature review}

In the debate on pain in farm animals, the Ministry of Agriculture first leaned toward breeders' organizations. On the eve of the Rencontres, it declared itself in favor of maintaining existing legislation and practice. ${ }^{20}$ Like the breeders, the Ministry made the economic survival of French livestock businesses a central component of its policy image: "Risks of a distortion [of competition] between France and third countries are real (...). [Animal welfare] standards must remain at a level that preserves the economic viability of farming activities". ${ }^{21}$ In addition, the Ministry emphasized that the European Union was competent in this area. It made any reform conditional upon the adoption of an agreement at the European level. ${ }^{22}$ At most, the Ministry referred to the need to conduct further scientific research on the question-a position that can be interpreted both as an obstacle and an opportunity to reform. ${ }^{23}$

It is on this specific point- the need to conduct further research-that the two coalitions seemingly came to an agreement during the Rencontres. Representatives of animal welfare organizations asked for an experimental study on stunning. They wanted to highlight that reversible stunning could both limit pain in farm animals and satisfy religious dietary restrictions. ${ }^{24}$ On this topic, uncertainty persisted-due to the lack of recent and robust scientific evidence. ${ }^{25}$ Religious leaders also argued that more scientific research was needed. However, they wanted to demonstrate that ritual slaughter was not the cause of additional pain for farm animals - as compared to slaughter with prior stunning. ${ }^{26}$ In brief, animal welfare and religious organizations had conflicting expectations regarding the goal of the study. Yet, elected officials in charge of moderating the roundtable embraced the idea of commissioning further scientific research on the subject. ${ }^{27}$

Under the growing pressure of animal welfare organizations, the Ministry of Agriculture shifted toward more of a middle-ground position. At the end of the Rencontres, in the summer of 2008, the Ministry included and specified the study proposal in its 34-point action plan. It stipulated that INRA would be entrusted with a

\footnotetext{
20 Talking Points for the Minister of Agriculture, 2006, Ministry of Agriculture.

21 Ibid.

22 Ibid.

23 Ibid.

24 "M. [D], representative of the OABA: associations ask for (...) a study (...) that would investigate the conditions under which stunning can be reversed. It is important to better understand when stunning by an electric shock is reversible, in accordance with religious dietary restrictions" (Minutes, Roundtable, 7 May 2008, Ministry of Agriculture).

25 "I wanted a scientific study on this particular point [a comparison of animal pain, with and without stunning] (...). Some research work had been done on the topic (...). But it was old stuff. There was little data from robust experiments in France. Data was scattered" (Interview, Animal welfare organization, 2016).

26 "For Chief Rabbi [A] (...): when ritual slaughter is performed by the book, it does not cause greater suffering of the animal (...). It would be interesting to have more scientific data on this topic" (Minutes, Roundtable, 7 May 2008, Ministry of Agriculture).

27 Minutes, Roundtable, 7 May 2008, Ministry of Agriculture.
} 
study investigating the pain felt by farm animals, with a special focus on slaughter. ${ }^{28}$ The study would not be experimental; a systematic literature review was expected (Expertise Collective or ESCO, in French).

For the Ministry of Agriculture, INRA was qualified both to tackle the subject of animal welfare and to employ the systematic literature review method. ${ }^{29}$ INRA had a long history of working on pain in farm animals: ${ }^{30}$ its researchers organized seminars and conducted research ${ }^{31}$ on the subject. Second, INRA had already successfully carried out five systematic literature reviews before 2008-including four on behalf of the Ministry of Agriculture.

For the Ministry's policymakers, commissioning a systematic literature review from INRA had several advantages. First and foremost, it provided an opportunity to partially satisfy the expectations of both sets of actors: the animal rights activists' expectations of taking action and reforming the livestock sector ${ }^{32}$ and the breeders' expectations of maintaining the status quo (now echoed by the Presidency of the Republic). ${ }^{33}$ It allowed the Ministry to avoid the blame associated with non-decision $^{34}$ by maintaining the image of an ideal bureaucracy addressing problems within its jurisdiction and mobilizing logical reasoning and scientific knowledge for their resolution (Boswell 2008). In this regard, the commissioning falls into the category of agenda limitation strategies ("The best way for policymakers to keep a blamegenerating issue from hurting them politically is to keep it off the agenda in the first place"; "Controversial issues may, for example, be delegated to study commissions with instructions to report just after the election" (Weaver 1986, pp. 384-386)). In the longer term, commissioning a systematic literature review had the advantage of potentially identifying new farming and slaughter practices that could have less detrimental consequences for French livestock businesses (practices that are less painful for farm animals and that do not lead to an increase in production costs):

It was a pragmatic approach: we could ask breeders to change their current practice, but there is not really any alternative at the moment (...). At the same time, animal welfare organizations are asking to put an end to some practices immediately (...). In the end, maybe science can help us find a middle ground

\footnotetext{
28 Minutes, Closing Meeting of the Rencontres Animal et société, 8 July 2008, Ministry of Agriculture.

29 "At the time, there were only two people working on animal welfare at the ANSES. Overall, INRA had more legitimacy. Besides, INRA had developed the methodology of Expertise Collective" (Interview, Ministry of Agriculture, 2016).

30 "We had a certain number of skills, in house (...), to carry out [Expertise Collective]. At the same time, at the scientific level (...), there was (...) the Agri-Animal Welfare Group (...), which brought together all actors working on animal welfare in France, and was led by INRA" (Interview, INRA, 2017).

31 See the research and activities of the Agribea and Neurosciences research networks.

32 "Something had to be done, this was a request from animal welfare organizations" (Interview, Ministry of Agriculture, 2016).

33 "There was a moment when we wanted to move forward (...) on the legal status of animals. But there were clear instructions not to go any further because the profession was clearly opposed to it" (Interview, Ministry of Agriculture, 2017).

34 "That's it! We didn't want to take any action [because] we realized that pain in farm animals is a complicated issue" (Interview, Ministry of Agriculture, 2016).
} 
(...) what alternatives could we come up with? (Interview, Ministry of Agriculture 2016).

The rationale behind the commissioning of the review shows that the Ministry of Agriculture played the role of a policy broker. However, animal welfare organizations were not fooled by Ministry of Agriculture's maneuver ${ }^{35}$ Disappointed by its action plan ["The mountain had given birth to a mouse" (Interview 2016)]-which was limited to measures to inform consumers, train clergymen in charge of ritual slaughter, and enforce existing laws ${ }^{36}$ —organizations resumed their communication campaigns, this time targeting the Ministry. The strategy was the same. In a joint open letter, France Nature Environnement (FNE) publicly criticized the Ministry's action plan ("very insufficient"; "limited to a few negligible improvements") and its decision to commission a review ("What is urgent is not to study pain-we know it well enough!-but to fight it"). ${ }^{37}$ At the end of 2008, animal welfare organizations announced their departure ${ }^{38}$ from the Commission nationale de suivi-an advisory body set up by the Ministry after the Rencontres to assist in implementing the action plan.

As constant pressures to regulate (and not to regulate) show, the Ministry of Agriculture falls into the category of an action organization. Its legitimacy, in the eyes of stakeholders, derives from its action and impact on society (the regulation of livestock production), rather than merely from its talks and decisions (Brusson 2002; cited in Boswell 2008, p. 474).

\section{The debate moves toward the management of the review}

In this particular context, INRA launched its systematic literature review on pain in farm animals. It is worth noting here that the Ministry of Agriculture and the Ministry of Research (which then joined the process as a co-sponsor) used the commissioning of the review as an attempt to redefine the issue-from the prevention to the management of animal pain. The comparison of different versions of the terms of reference shows the evolution of the Ministries' research questions. While a draft version concentrated on the relationship between pain felt by animal farms and farming practices (e.g., debeaking, dehorning) including slaughter, the final version focused on the definition and measurement of pain and its consequences for animals. ${ }^{39}$ In this regard, the commissioning of the review falls into another category of blame-avoiding strategies ["if policymakers cannot keep a blame-generating issue

\footnotetext{
35 "You know... when there's a social issue that people can be very upset about, and [policymakers] set up a committee or a group? That's how we felt [about the review]" (Interview, Animal welfare organization, 2016).

36 Minutes, Closing Meeting of the Rencontres Animal et société, 8 July 2008, Ministry of Agriculture.

37 Press Release. Rencontres Animal et société: des actes!, 12 Feb. 2009.

38 Letter to the Minister of Agriculture, 19 Dec. 2008, Animal Welfare Organizations.

39 Draft and final versions of: Letter from the Minister of Agriculture and the Minister of Research to the CEO of INRA, 2008, 2009, Ministry of Agriculture, Ministry of Research.
} 
off the agenda, they may be able to reshape it in such a way as to prevent blame" (Weaver 1986, p. 386)].

On the basis of the Ministries' terms of references, INRA formalized a study proposal in September 2008. It mobilized extensive financial and human resources: INRA's management and its expertise unit, an ad hoc panel bringing together inhouse and external academic experts from different disciplines (INRA 2009). The review's production process (selection of experts, literature search and analysis, writing of the report) took more than 1 year (Ibid.).

Representatives from animal welfare and breeders' organizations were involved in the production process - as members of the Steering committee, alongside officials from the Ministry of Agriculture and the Ministry of Research. Both coalitions used the Steering committee as an opportunity to (re)state their positions. Animal rights activists faulted the systematic literature review method for not being relevant to the issue: they called for an experimental study focusing on stunning. ${ }^{40}$ Breeders highlighted the uncertainty of both the suffering of farm animals at the slaughter stage and the feasibility of implementing less painful farming practices. ${ }^{41}$ The review's production process saw both coalitions align along disciplinary lines. A member of the panel of experts in charge of reviewing the literature highlighted the epistemological gap between, on one hand, sociologists, ethics specialists, and philosophers and on the other, zootechnicians, and economists: "A number of zootechnicians are here to increase productivity"; "For [K, a philosopher]: the question isn't about how we handle breeding, it's about how we suppress it" (Interview 2016). Animal welfare organizations advocated for giving ethics a more prominent role within the review: "Mr. $[G]$ (...): there is a real risk for ethics to be given short shrift here"; "Ms. [H] is concerned that the study is too neutral from an ethical viewpoint-it must take a stand". ${ }^{42}$ Breeders' organizations criticized the "convoluted questions" and questioned the overall relevance of ethics. ${ }^{43}$ They called for taking greater stock of economic data. ${ }^{44}$

\footnotetext{
$40 \mathrm{Mr}$ [A] reiterates that he hoped for an experiment focusing on stunning, rather than for bibliography on ritual slaughter"; "He regrets that no technical evaluation of the conditions in which stunning takes place (...) is undertaken" In: Minutes, Meeting 2 of the Steering Committee of the Expertise Collective, 16 Jun. 2009, Ministry of Agriculture.

41 "Mr. [I]: We must address the question of the loss of sensitivity (...). On [the] topic, there are still some research gaps" In: Ibid.

${ }^{42}$ Minutes, Meeting 2 of the Steering Committee of the Expertise Collective, 16 Jun. 2009, Ministry of Agriculture.

43 "We can ask ourselves the question of how animals really feel and experience pain, emotionally (...). There always will be scientific questions (...) [but] we're into a level of detail that doesn't speak to the majority of people" (Interview, Breeders' organization, 2017).

44 "M. [I]: what are the limits when it comes to socio-economic aspects?» In: Minutes, Meeting 2 of the Steering Committee of the Expertise Collective, 16 Jun. 2009, Ministry of Agriculture.
} 


\section{Results and discussion}

The six hypotheses on the legitimizing function of expert information (when policymakers use knowledge as a substitute for decision and the primary objective of the commissioning is to send signals to other actors within the subsystem and to preserve and extend their jurisdiction) were tested on the basis of the description of the context in which the Ministry of Agriculture commissioned INRA to carry out a systematic literature review on animal pain.

At the policy subsystem level, the legitimizing function is hypothetically associated with an adversarial policy subsystem (H1) (Boswell 2008; Radaelli 2009; Schrefler 2010; Rimkuté 2015), and a concentration of policy authority in the hands of a single organization (H6) (Daviter 2015). Overall, evidence from our case study supports $\mathrm{H} 1$ and H6, notwithstanding some nuances regarding the instability of the organizational field. The case exhibits an adversarial policy subsystem with two opposing advocacy coalitions. Animal welfare organizations held as deep core and policy core beliefs animal welfare and the regulation (if not the prohibition) of painful breeding and slaughter practices (shared beliefs). They collectively designed and implemented a number of political moves such as the writing of open letters (strong coordination). A second coalition brought together religious and breeders' organizations. They sought to maintain the status quo regarding the regulation of the livestock sector (policy core beliefs), the former because of the Scriptures and the latter to ensure the survival and profitability of their businesses (deep core beliefs). While their activities were not collectively designed and implemented, they complemented each other (e.g., exchange of arguments at the Rencontres) (weak coordination). Both advocacy coalitions coordinated policy activities to outmaneuver each other. They exerted formal and informal pressures on the Ministry of Agriculture. Animal rights activists, religious leaders, and breeders displayed opposing policy images supporting their beliefs before the Ministry-before, during, and after the Rencontres Animal et société. Pressures continued during the production process of the INRA review. However, no evidence suggests that the organizational field was unstable [in the sense that the organization commissioning the production of new knowledge (the Ministry of Agriculture) was uncertain about its survival; or that competitors (the Ministry of Interior and Cults, the Ministry of Research) disputed the allocation of power and resources (Boswell 2008, p. 473)]. Policy authority was consensually concentrated in the hands of the Ministry of Agriculture.

At the organizational level, hypotheses of the legitimizing function of expertise are the political nature of the organization commissioning the production of new knowledge (Boswell 2008) (H2) and a low internal scientific capacity of the organization commissioned to produce new knowledge (Schrefler 2010; Rimkuté 2015) (H3). The empirical analysis shows that these two factors are not essential to the legitimizing function of expert information. As the Ministry of Agriculture draws its legitimacy from its outputs (the regulation of the livestock sector), it falls into the category of action organizations, rather than political ones. Besides, INRA had strong internal capacities to produce solid scientific expertise on pain 
in farm animals - and was seen as such by the Ministry of Agriculture and stakeholders. In addition, the case study suggests that the legitimizing function of expert information is associated with a role of policy broker for the organization commissioning the production of new knowledge (Observation 1). The latter role consists of mitigating conflict between rival advocacy coalitions (Weible and Ingold 2018, p. 332). The previous description shows that the Ministry of Agriculture refused to fully align with the position of animal rights activists (a more stringent regulation of breeding practice) or with the position of breeders and clergymen (maintaining the status quo). In this situation of non-decision, the Ministry used the commissioning of an INRA review as a double blame-avoiding strategy of agenda limitation and issue redefinition (Weaver 1986, pp. 384-386). Policymakers managed to delay the decision-making process for a year (until the publication of the final report) while trying to redefine the issue-from preventing to managing animal pain. At the same time, the commissioning allowed the Ministry to maintain the image of an ideal bureaucracy, addressing problems within its jurisdiction and mobilizing logical reasoning and scientific knowledge for their resolution (Boswell 2008, p. 471).

At the problem level, the legitimizing function of knowledge is hypothetically associated with a low level of analytical tractability of the problem at stake (Boswell 2008: Schrefler 2010) (H4). In addition, the degree of media attention to the problem may have limited influence on the type of knowledge use (Weible 2008; Schrefler 2010) (H5). Evidence from this case study supports H4 and H5. Notwithstanding the stock of knowledge on pain in farm animals, both advocacy coalitions shed light on a series of distinct epistemic uncertainties (e.g., To which extent animal pain varies according to the type of slaughter practice? What are the consequences of more regulated breeding practices on the profitability of livestock businesses?). Communication campaigns by animal welfare organizations (and later the Ministry of Agriculture's commissioning of a systematic literature review) received little coverage in the national media.

Factors of the legitimizing function of expert information are now integrated into a Tilly-like process-based account. The latter function requires environmental mechanisms (Tilly 2001) (features of the policy subsystem) to occur: an adversarial policy subsystem (H1) and a concentration of policy authority in the hands of a single organization (H6). The legitimizing function also demands a particular sequence of relational mechanisms (Ibid.). First, rival advocacy coalitions must exert high formal and informal pressures on the organization which concentrates policy authority, using opposing policy images (H1). At this stage, they do not need to extend the conflict beyond the subsystem (e.g., mass media communication strategies and press coverage) (H5). Second, all coalitions must display some epistemic uncertainty regarding the problem, its causes, and its consequences (H4). The very nature of uncertainty may differ between coalitions. Third, the organization which concentrates policy authority must take up the role of a policy broker and refuse to fully align itself with the position of one coalition or the other (O1). Finally, the policy broker commissions the production of new knowledge as a strategy to limit the agenda and to redefine the issue. It may commission an organization with a low internal capacity to produce scientific outputs in order to scuttle the production 
process (H3). It may also commission the most comprehensive form of expertise (a systematic literature review) in order to delay the decision-making process.

This article has developed a theory explaining differences in expert knowledge use, tested in one particular context-when and why the French Ministry of Agriculture commissioned INRA to carry out a systematic literature review on pain in farm animals. In accordance with Baumgartner and Jones (2005), it highlights that a clear, consensual concentration of policy authority may be detrimental to the search for new expert information on policy problems and solutions. Future research should test the explanations outlined here in different settings (e.g., ministries in other policy sectors and/or from other countries).

Acknowledgements This research was supported by the Belgian Fonds de la Recherche Scientifique (FRS-FNRS) (PDR T.0062.18). Additional support was provided by the Maison Interuniversitaire des Sciences de l'Homme d'Alsace (MISHA) and the Excellence Initiative of the University of Strasbourg.

Open Access This article is licensed under a Creative Commons Attribution 4.0 International License, which permits use, sharing, adaptation, distribution and reproduction in any medium or format, as long as you give appropriate credit to the original author(s) and the source, provide a link to the Creative Commons licence, and indicate if changes were made. The images or other third party material in this article are included in the article's Creative Commons licence, unless indicated otherwise in a credit line to the material. If material is not included in the article's Creative Commons licence and your intended use is not permitted by statutory regulation or exceeds the permitted use, you will need to obtain permission directly from the copyright holder. To view a copy of this licence, visit http://creativecommons.org/licen ses/by/4.0/.

\section{References}

Baumgartner, F., and Jones, B. 2005. The Politics of Attention: How Government Prioritizes Problems. Chicago: University of Chicago Press.

Bédard, P.O., and M. Ouimet. 2017. Awareness and Use of Systematic Literature Reviews and MetaAnalyses by Ministerial Policy Analysts. Canadian Public Administration 60 (2): 173-191.

Blatter, J., and M. Haverland. 2012. Designing Case Studies. Exploratory Approaches in Small-n Research. Basingstoke: Palgrave Macmillan.

Boswell, C. 2008. The Political Functions of Expert Knowledge: Knowledge and Legitimation in European Union Immigration Policy. Journal of European Public Policy 15 (4): 471-488.

Brunsson, N. 2002. The Organization of Hypocrisy: Talk, Decisions and Actions in Organizations. Copenhagen: Abstrakt and Liber.

Coleman, J. 1972. Policy Research in Social Science. Morristown: General Learning Press.

Collins, H. 1981. Son of Seven Sexes: The Social Destruction of a Physical Phenomenon. Social Studies of Science 11 (1): 33-62.

Daviter, F. 2015. The Political Use of Knowledge in The Policy Process. Policy Sciences 48(4): 491-505.

Gunderson, L., and S. Light. 2006. Adaptive Management and Adaptive Governance in the Everglades Ecosystem. Policy Sciences 39(4): 323-334.

Hertin, J., J. Turnpenny, A. Jordan, M. Nilsson, D. Russel, and B. Nykvist. 2009. Rationalizing the Policy Mess? Ex-ante Policy Assessment and the Utilization of Knowledge in The Policy Process. Environment and Planning A 41(5): 1185-1200.

INRA. 2009. Douleurs animales : les identifier, les comprendre, les limiter chez les animaux d'élevage. Paris: INRA.

Jasanoff, S. 1990. The Fifth Branch: Science Advisers as Policymakers. Cambridge: Harvard University Press.

Jenkins-Smith, H.C., and P.A. Sabatier. 1993. Policy Change and Learning: An Advocacy Coalition Approach. Boulder: Westview Press. 
Knorr, K. 1976. Policy-Makers Use of Social Science Knowledge: Symbolic or Instrumental?. Vienna, Austria: Institute for Advanced Studies Vienna. IHS Research Memoranda no. 103.

Knorr, K. 1977. Policy-Makers Use of Social Science Knowledge: Symbolic or Instrumental? In Using Social Research in Public Policy Making, ed. C. Weiss, 165-181. Lexington: Lexington Books.

Nelkin, D. 1975. The Political Impact of Technical Expertise. Social Studies of Science 5(1): 35-54.

Neuendorf, K. 2019. Content Analysis and Thematic Analysis. In Advanced Research Methods for Applied Psychology: Design, Analysis and Reporting, ed. P. Brough, 211-224. Abingdon: Routledge.

Norton, B. 2005. Sustainability: A Philosophy of Adaptive Ecosystem Management. Chicago: University of Chicago Press.

Oh, C., and R. Rich. 1996. Explaining Use of Information in Public Policymaking. Knowledge and Policy 9(1): 3-35.

Radaelli, C. 1995. The Role of Knowledge in The Policy Process. Journal of European Public Policy 2(2): $159-183$.

Radaelli, C. 2009. Measuring Policy Learning: Regulatory Impact Assessment in Europe. Journal of European Public Policy 16(8): 1145-1164.

Radaelli, C., and B. Dente. 1996. Evaluation Strategies and Analysis of Policy Process. Evaluation 2(1): 51-66.

Rimkutè, D. 2015. Explaining Differences in Scientific Expertise Use: The Politics of Pesticides. Politics and Governance 3(1): 114-227.

Rohlfing, I. 2012. Case Studies and Causal Inference: An Integrative Framework. Basingstoke: Palgrave Macmillan.

Sabbagh, C., Y. Le Bars, and P. Stengel. 2014. Des expertises scientifiques crédibles en appui à la décision et au débat publics. Natures Sciences Sociétés 22 (4): 366-372.

Scholz, T., and B. Stiftel (eds.). 2005. Adaptive Governance and Water Conflict: New Institutions for Collaborative Planning. Washington DC: Resources for the Future Press.

Schrefler, L. 2010. The Usage of Scientific Knowledge by Independent Regulatory Agencies. Governance 23(2): 309-330.

Tilly, C. 2001. Mechanisms in Political Processes. Annual Review of Political Science 4 (1): 21-41.

Weaver, R. 1986. The Politics of Blame Avoidance. Journal of Public Policy 6(4): 371-398.

Weible, C. 2008. Expert-Based Information and Policy Subsystems: A Review and Synthesis. Policy Studies Journal 36(4): 615-635.

Weible, C., and K. Ingold. 2018. Why Advocacy Coalitions Matter and Practical Insights About Them. Policy and Politics 46(2): 325-343.

Weible, C., and P. Sabatier. 2009. Coalitions, Science, and Belief Change: Comparing Adversarial and Collaborative Policy Subsystems. Policy Studies Journal 37 (2): 195-212.

Weible, C.M., K. Ingold, D. Nohrstedt, A.D. Henry, and H.C. Jenkins-Smith. 2020. Sharpening Advocacy Coalitions. Policy Studies Journal 48 (4): 1054-1081.

Weiss, C. 1979. The Many Meanings of Research Utilization. Public Administration Review 39(5): 426-431.

Publisher's Note Springer Nature remains neutral with regard to jurisdictional claims in published maps and institutional affiliations. 